American Journal of Applied Sciences 7 (4): 535-539, 2010

ISSN 1546-9239

(C) 2010Science Publications

\title{
Asymmetry Effect of Inflation on Inflation Uncertainty in Iran: Using from EGARCH Model, 1959-2009
}

\author{
${ }^{1}$ Dahmardeh Nazar, ${ }^{1}$ Pourshahabi Farshid and ${ }^{2}$ Khani Zade Amiri Mojtaba \\ ${ }^{1}$ Department of Economics, Sistan and Baluchestan University, Zahedan, Iran \\ ${ }^{2}$ Department of Economics, Esfahan University, Esfahan, Iran
}

\begin{abstract}
Problem statement: In this study, we tried to examine the relationship between inflation and inflation uncertainty in Iran, because of considerable variation in its inflation rate. Approach: Inflation uncertainty is the major cost of high inflation that can influence the decision making of economic agents. Results: This study constructed a time series of seasonally inflation uncertainty in Iran from 1959-2009 and investigated the relationship between inflation and inflation uncertainty. We modeled inflation uncertainty at time varying process through EARCH framework. Also, the asymmetric and consistence behavior of inflation uncertainty was analyzed by using this method. The result showed that there was an asymmetric relationship between inflation and inflation uncertainty and shocks inflation uncertainties do not die out rapidly. Thus, the positive shocks had a greater effect on uncertainty rather than negative shocks. In final, we investigated from the Granger Causality test that inflation was Granger Causality of inflation uncertainty. Conclusion/Recommendations: The results of study recommend to aiming at low average inflation rates in order to reduce the negative consequences of inflation uncertainty.
\end{abstract}

Key words: Inflation uncertainty, EGARCH, Iran

\section{INTRODUCTION}

Inflation is one of the most important economic variable both theoretically and empirically. Inflation uncertainty that generated from inflation volatility is one of the major cost of inflation that can influence the decision making of economic agents. We can't say that inflation is harmful or useful for an economy but we can say that inflation uncertainty is harmful. Inflation uncertainty has the negative effect on economic variables such as: growth, consumption, investment, money demand and other. The relationship between inflation and inflation uncertainty has attracted considerable attention since the publication of Milton Friedman's Nobel lecture. Friedman (1977) was the first who formalized the relationship between inflation and inflation uncertainty and He strongly supported the causality link that running from inflation to inflation uncertainty.

Golob (1994) argues that inflation uncertainty is one of the most important costs of inflation, it creates about future inflation. Uncertainty about inflation similar to expected inflation is a factor in an economic decision. For example, uncertainty about future inflation can affect both business investment and decisions and consumer saving decisions. He says that inflation uncertainty has two types of economic effects. Ex-ante effect that inflation uncertainty leads to change in decision making from the ones they would make otherwise. The next effect is ex-post effect that takes place after the decisions have been made. He says that this is the response of monetary policy that leads to inflation uncertainty because the timing and short run impact of policy on inflation is uncertain. He suggested that to minimize the disruptions to economic decision making by inflation uncertainty, the Federal Reserve should continue to work toward price stability (Golob, 1994).

Engle (1982) was the first who modeled inflation uncertainty as Autoregressive Conditional Heteroskedasticity (ARCH). He used conventional inflation equation with fixed parameters and allowed the conditional variance of inflation shocks to vary over the time. He suggested that the conditional variance of unpredictable shocks to the inflation could be used as proxy for inflation uncertainty (Engle, 1982). Bollerslev (1986) developed the Generalized ARCH (GARCH) model, in which the conditional variance is a function of lagged values of forecast errors and the conditional variance.

This study focuses on the inflation-uncertainty relationship by using a seasonally series of Iran

Corresponding Author: Pourshahabi Farshid, Department of Economics, Sistan and Baluchestan University, Zahedan, Iran 
Am. J. Applied Sci., 7 (4): 535-539, 2010

inflation rates, a period characterized by significant variability of the inflation rate. For this period, we find strong evidence in favor of the Friedman-Ball hypothesis. We explain this linkage by estimating a conditional variance series using the EGARCH technique. This flexible GARCH model allows for an asymmetric response of inflation uncertainty to positive and negative inflation shocks. The rest of the study is outlined as follows: At first provides a review of the literature on measuring inflation uncertainty and the results from past studies, in continue, discusses the data and methodology and discusses the empirical results. Finally, we present summarizes the major conclusions.

Literature review: Friedman (1977) suggests a positive correlation between the level of inflation and inflation uncertainty, with higher inflation leading to greater uncertainty and lower output growth. The literature that explores the relation between inflation and inflation uncertainty centers on the empirical estimation of inflation uncertainty that conforms to the notion of uncertainty as set forth by Friedman. This literature then uses causality tests to establish the relation between inflation and the estimated measures of inflation uncertainty (Friedman, 1977). Okun (1971) shows that the countries with high standard deviation of inflation are the countries that experiencing high inflation rate. He argued that inflation is positively associated with inflation uncertainty that created by more unpredictable monetary policy that caused by high inflation (Okun, 1971).

Demetriades (1988) shows that in the presence of asymmetric information between the policymaker and the public and asymmetric stabilization policies (a greater policy response to negative shocks than positive shocks), there will be a positive relationship between the inflation rate and its variance. Ball (1992) formalizes Friedman's argument in the context of model in which more inflation associated by more uncertainty over the monetary policy stance. He argues that there are two types of policymakers that one type would like to reduce inflation but another of type fear that it would lead to recession. Therefore, economic agents will be highly uncertain about the future taste of policymakers and consequentially about future inflation (Ball, 1992).

Cukierman and Meltzer (1986) asserted that the causality running in opposite direction from inflation uncertainty to inflation that well known as Cukierman and Meltzer hypothesis. They argue that increases in inflation uncertainty raise the optimal inflation rate by increasing the incentive for the policy maker to create inflation surprises in a game theoretical framework (Cukierman and Meltzer, 1986).
Engle (1983) employs an Autoregressive Conditional Heteroskedasticity (ARCH) model to estimate the conditional mean and variance of inflation from US data. ARCH models provide time-varying estimates of the conditional variance of inflation, specified as a linear function of current and past squared forecast errors (Engle, 1983). Evans (1991) employs an ARCH model in his study; he finds that the relationship between inflation and inflation uncertainty is positive, but does not establish causation. Bollerslev (1986) develops a Generalized ARCH (GARCH) model in which the time-varying estimates of the conditional variance also include past variances. He finds that the conditional variance does not appear to be closely related to inflation (Bollerslev, 1986).

Johnson (2002) measures uncertainty as the SD of individual forecasts within a calendar year and as the average next-year forecast error. He finds that, there is positive link between past inflation and current uncertainty similar to Friedman-Ball hypothesis (Johnson, 2002). Devereux (1989) discussed that causal link running from variance of inflation to the average rate of inflation. He represents a theoretical framework by exploiting a model of discretionary monetary policy which incorporated real disturbance and endogenous wag indexation (Devereux, 1989). Neyapti (2000) by using an Autoregressive Conditional Heteroskedasticity (ARCH) shows that high inflation associated with more uncertainty of wholesale price inflation in Turkey between 1982-1999. Nas and Perry (2000) constructed a time series of monthly inflation uncertainty in Turkey from 1960-1998 using GARCH models. They finds that inflation significantly raised inflation uncertainty over the full sample and three subsample but the evidence on the effect of inflation uncertainty on average inflation is mixed and depends on the sample (Nas and Perry, 2000).

Holland (1995) argued that if central bank attempts to minimize the welfare losses arising from inflation uncertainty, then greater inflation uncertainty leads to lower average inflation rate, not higher inflation rate. Fountas et al. (2004) find that inflation causes inflation uncertainty for France and Italy, but not Germany. Also, they find that uncertainty causes inflation for France and Germany with a negative sign. They used EGARCH model in their study (Fountas et al., 2004).

Brunner and Hess (1993) and Caporale and McKiernan (1997) all provide evidence for the positive association between the mean and the variance of inflation, both across countries and over time for the US. Brunner and Hess (1993) argue that the GARCH model places symmetry restrictions on the conditional variance that are differing with Friedman-Ball 
hypothesis. This hypothesis represented that when inflation is low then inflation uncertainty lower that high inflation situation (Brunner and Hess, 1993). Thornton (2008) examines the relationship between inflation and inflation uncertainty, by using GARCH $(1,1)$ model in his estimates. The result of this study shows a positive short run relation between the mean and variance of inflation. On the Basis of this study Friedman's Hypothesis is supported. Therefore, high inflation is associated with more variable inflation (Thornton, 2008).

\section{MATERIALS AND METHODS}

Data and methodology: The data used are seasonally Consumer Price Index (CPI) of Iran economy from 1959-2009. Data of central bank of Iran have been used as the source data. Also, we applied EGARCH model for capture volatility. Autoregressive Conditional Heteroscedasticity (ARCH) type modeling is the predominant statistical technique employed in the analysis of time-varying volatility. In ARCH models, volatility is a deterministic function of historical returns. The original ARCH (q) formulation proposed by Engle (1982) model of conditional variance has a linear function of the first q past squared innovations:

$$
\mathrm{h}_{\mathrm{t}}=\omega+\sum_{\mathrm{i}=1}^{\mathrm{q}} \alpha_{\mathrm{i}} \varepsilon_{\mathrm{t}-\mathrm{i}}^{2}
$$

Several models have been provided to investigate the Asymmetric effects in GARCH models. In this study we employ the asymmetric Exponential GARCH (EGARCH) model proposed by Nelson (1991). The GARCH model requires non-negative coefficients, since the EGARCH specification models the logarithm of the conditional variance and does not impose nonnegativity constraint (Nelson, 1991). The mean and variance equations of the $\mathrm{AR}(\mathrm{p})$-EGARCH$(1,1)$ model can be expressed as:

$$
\pi_{\mathrm{t}}=\alpha_{0}+\sum_{\mathrm{i}=1}^{\mathrm{p}} \mathrm{a}_{\mathrm{i}} \pi_{\mathrm{t}-\mathrm{i}}+\varepsilon_{\mathrm{t}}
$$

$$
\log \mathrm{h}_{\mathrm{t}}=\alpha_{0}+\alpha_{1} \log \mathrm{h}_{\mathrm{t}-1}+\beta\left|\frac{\varepsilon_{\mathrm{t}-1}}{\mathrm{~h}_{\mathrm{t}-1}}\right|+\gamma \frac{\varepsilon_{\mathrm{t}-1}}{\sqrt{\mathrm{h}_{\mathrm{t}-1}}}
$$

If $\gamma$ is non-zero, the impact of inflation on inflation uncertainty is asymmetric, when $\gamma$ is positive an increase in inflation causes more inflation uncertainty, since a decrease in inflation produces less uncertainty.
This interaction is similar to that of Friedman. Furthermore, the flexibility of this asymmetry, the logarithm specification assumes greater weight is placed on higher levels of inflation in estimating uncertainty, which confirms to Friedman-Ball hypothesis.

Also, we employ Granger Causality tests to explore the linkage between inflation and inflation uncertainty. The standard Granger Causality test is a test of temporal ordering between two variables, allowing us to examine whether inflation $\left(\pi_{\mathrm{t}}\right)$ precedes inflation uncertainty $\left(\mathrm{h}_{\mathrm{t}}\right)$ and whether inflation uncertainty precedes inflation. To examine these tests, we use the following equations:

$$
\begin{aligned}
& \mathrm{h}_{\mathrm{t}}=\alpha_{0}+\sum_{\mathrm{i}=1}^{\mathrm{k}} \alpha_{\mathrm{i}} \mathrm{h}_{\mathrm{t}-\mathrm{i}}+\sum_{\mathrm{i}=1}^{\mathrm{k}} \beta_{\mathrm{i}} \pi_{\mathrm{t}-\mathrm{i}}+v_{\mathrm{t}} \\
& \pi_{\mathrm{t}}=\gamma_{0}+\sum_{\mathrm{i}=1}^{\mathrm{k}} \gamma_{\mathrm{i}} \pi_{\mathrm{t}-\mathrm{i}}+\sum_{\mathrm{i}=1}^{\mathrm{k}} \delta_{\mathrm{i}} \mathrm{h}_{\mathrm{t}-\mathrm{i}}+\eta_{\mathrm{t}}
\end{aligned}
$$

Equation 4 is used to test whether inflation causes inflation uncertainty while Eq. 5 is used to test whether inflation uncertainty causes inflation.

\section{RESULTS AND DISCUSSION}

It is necessary to check the order of integration of inflation rate series before we continue the inflation uncertainty models. Therefore, at first, we examine the stationary of inflation variable by using Phillips-Perron test.

Figure 1 illustrates the volatility of price changes over the period; also Table 1 shows the summary statistics for the inflation series. The value of the Jarque-Bera statistics implies a deviation from normality, the significantly of Q statistics and LM(1) statistics indicate that the squared deviation of the inflation rate from the sample means indicates the existence of ARCH effects.

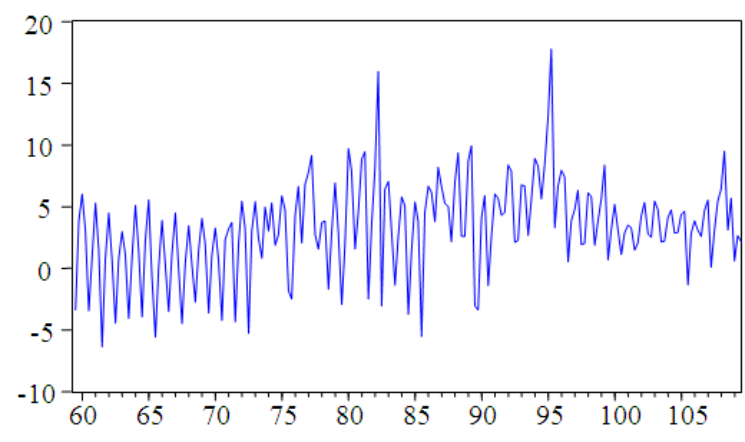

Fig. 1: Iran Inflation, 1959-2009 
Am. J. Applied Sci., 7 (4): 535-539, 2010

Table 1: Summery statistics for consumer price inflation, 1959-2009

\begin{tabular}{lc}
\hline Mean & 3.250319 \\
\hline Median & 3.193305 \\
Maximum & 17.77595 \\
Minimum & -6.357280 \\
Std. Dev. & 3.779731 \\
Skewness & 0.034870 \\
Kurtosis & 4.142906 \\
Jarque-Bera (Probability) & $10.98044(0.004)$ \\
$\mathrm{Q}^{2}$ & $6.3020(0.012)$ \\
$\mathrm{LM}(1)$ & $6.311521(0.0128)$ \\
\hline $\mathrm{Q}^{2}$ is the Ljung-Box test for serial correlation in the squared \\
deviations of the inflation rate from its sample mean, where the 1st \\
order test statistic is reported; LM(1) is the Engle test for ARCH \\
effects. Values in parenthesis are p-values \\
\multicolumn{2}{l}{ Table 2: Unit root tests results for consumer inflation, $1959-2009$} \\
\hline Philips and Perron & $-12.06852 *(0.000)$ \\
\hline Test critical value & -4.004599 \\
$1 \%$ & -3.432452 \\
$5 \%$ & -3.139991 \\
$10 \%$ &
\end{tabular}

*: Indicates significance at the $95 \%$ level

Table 2 reports the Unit root test results for the inflation series. The result of this test indicates that inflation variable is stationary.

The maximum likelihood estimates of the GARCH model are reported in Table 3. The model selected lags briefly on the basis of the minimum value of the Schwarz Bayesian Criterion. The results strongly support the existence of a positive relationship between inflation and inflation uncertainty. The reported parameters in the inflation and covariance equations are highly significant and of the hypothesized signs. This model is able to accommodate for the asymmetric or leverage effect. The EARCH modeling is appropriate for modeling of most of economic and financial time series data since negative shocks and positive shocks have different effects on the conditional variance (volatility).

Table 3 reports the estimates of the estimated model. The results indicate that estimated model for both standardized residuals and standardized squared residuals are free from serial correlation and conditional heteroscedasticity. Thus, it specified that estimated EARCH model seems to be an adequate model. A Granger-causality test of the inflation-inflation uncertainty relation indicates that it is strongly causal and positive.

The coefficient of $\gamma$ is significant statistically at the $5 \%$ level. In this study, the positive and significant value of $\gamma$ coefficient implies that positive shocks have a greater impact on inflation uncertainty rather than negative shocks. Also, from the Table 3 we can investigate that shocks inflation uncertainties do not die out rapidly. We now turn to the result of Granger Causality tests. The results shown in Table 4 indicate that inflation is Granger causality of inflation uncertainty but the inverse relation is not observed.
Table 3: EGARCH(1,1) Model for inflation, 1959-2009

\begin{tabular}{llc}
\hline Variables & Coefficient & $\begin{array}{l}\text { Z-statistic } \\
\text { (probability) }\end{array}$ \\
\hline Inflation equation & & \\
Intercept & 0.086933 & $1.820290(0.0687)$ \\
P(-1) & 0.388834 & $7.100723(0.0000)$ \\
P(-3) & 0.205612 & $3.128820(0.0018)$ \\
P(-4) & 0.346877 & $6.137051(0.0000)$ \\
Seasonal dummy_1 & -0.019069 & $-4.142750(0.0000)$ \\
Seasonal dummy_2 & -0.066827 & $-12.64048(0.0000)$ \\
Seasonal dummy_3 & -0.024765 & $-5.819860(0.0000)$ \\
Variance equation & & \\
Intercept & -0.407140 & $-1.463864(0.1432)$ \\
ABS(RESID(1)/@SQRT & & \\
(GARCH (-1))) & -0.107418 & $-2.364768(0.0180)$ \\
RESID(-1)/@SQRT & & \\
(GARCH(-1)) & 0.357317 & $6.266485(0.0000)$ \\
LOG(GARCH(-1)) & 0.934437 & $25.71428(0.0000)$ \\
R2adj. & 0.569605 & \\
SBC & -4.628302 & \\
LM(1) & 0.225309 & \\
& $(0.6356)$ & \\
LM(2) & 1.395208 & \\
LM(3) & $(0.2503)$ & \\
& 1.373946 & \\
LM(4) & $(0.2520)$ & \\
& 1.030057 & \\
\hline
\end{tabular}

SBC: Schwarz Bayesian Criterion; LM1 is the ARCH LM test statistic of Chi-square (1)

Table 4: Granger causality test

\begin{tabular}{ll}
\hline Null hypothesis & F-statistic (probability) \\
\hline $\begin{array}{l}\text { Inflation uncertainty does not } \\
\begin{array}{l}\text { Inflation does not Granger } \\
\text { cause inflation uncertainty }\end{array}\end{array}$ & $1.27117(0.28273)$ \\
\hline
\end{tabular}

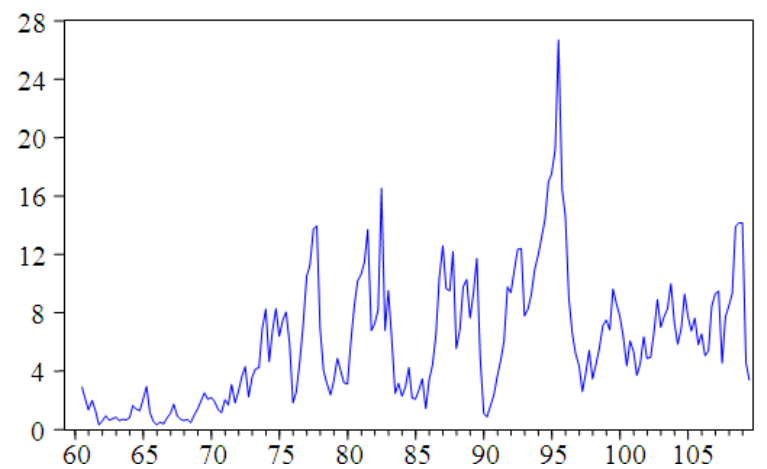

Fig. 2: Inflation uncertainty generated with EGARCH model from 1959-2009

Therefore, rising inflation raises inflation uncertainty and this result supports Friedman-Ball hypothesis in Iran economy. Figure 2 shows the inflation uncertainty generated by using EGARCH $(1,1)$ model. We can investigate that inflation uncertainty was observable from 1973. Also, the maximum of inflation uncertainty observed in 1995. 


\section{CONCLUSION}

The result of this study confirms the positive relationship between inflation and inflation uncertainty for the period 1959-2009 in Iran Economy. The method was used to capture the inflation uncertainty from inflation is the EGARCH model that proposed by Nelson. We find that EGARCH models are more successful in capturing inflation uncertainty and its asymmetric behaviors. The empirical results show that Friedman-Ball causal link strongly supports in Iran Economy. Therefore, higher inflation rate leads to higher level of inflation uncertainty. Also, the result of Granger causality test strongly supported the FriedmanBall hypothesis, this show that the causality is running from inflation to inflation uncertainty. In this study we gauge two features of inflation uncertainty, namely asymmetry and persistence of shocks. Thus, positive shocks have a greater effect on inflation uncertainty rather than negative shocks or shocks have asymmetric effects on the volatility of inflation and shocks inflation uncertainties do not die out rapidly. The policy implication in Iran is to aiming at low average inflation rates in order to reduce the negative consequences of uncertainty.

\section{REFERENCES}

Ball, L., 1992. Why does high inflation raise inflation uncertainty? J. Monetary Econ., 29: 371-388. DOI: 10.1016/0304-3932(92)90032-W

Bollerslev, T., 1986. Generalized autoregressive conditional heteroskedasticity. J. Econ., 31: 307327. DOI: 10.1016/0304-4076(86)90063-1

Brunner A.D. and G.D. Hess, 1993. Are higher levels of inflation less predictable? A state-dependent conditional heteroskedasticity approach. J. Bus. Econ. $\quad$ Stat., 11: 187-197. http://www.jstor.org/pss/1391370

Caporale, T. and B. McKiernan, 1997. High and variable inflation: Further evidence on the Friedman hypothesis. Econ. Lett., 54: 65-68. DOI: 10.1016/S0165-1765(96)00939-1

Cukierman, A. and A.H. Meltzer, 1986. A theory of ambiguity credibility and inflation under discretion and asymmetric information. Econometrica, 54: 1099-1128. http://www.jstor.org/pss/1912324

Demetriades, P., 1988. Macroeconomic aspects of the correlation between the level and variability of inflation. Econ. Lett., 26: 121-124. DOI: 10.1016/0165-1765(88)90025-0

Devereux, M., 1989. A Positive Theory of Inflation and Inflation Variance. Econ. Inquiry, 27: 105-116. DOI: 10.1111/j.1465-7295.1989.tb01166
Engle, R.F., 1982. Autoregressive conditional heteroskedasticity with estimates of the variance of UK inflation. Econometrica, 50: 987-1007. http://www.clarku.edu/faculty/mcallan/Econ273/Gr ad/papers/engle82.pdf

Engle, R., 1983. Estimates of the variance of US inflation rates based on the ARCH model. J. Money Credit Bank., 15: 286-301. http://www.jstor.org/pss/1992480

Evans, M., 1991. Discovering the link between inflation rates and inflation uncertainty. J. Money Credit Bank., 23: 169-184. http://www.jstor.org/stable/1992775

Fountas, S., A. Ioannidi and M. Karanasos, 2004. Inflation, inflation uncertainty, and a common European monetary policy. Manchester School, 72: 221-242. http://papers.ssrn.com/sol3/papers.cfm?abstract_id $=513781$

Friedman, M., 1977. Nobel lecture: Inflation and unemployment. J. Politic. Econ., 85: 451-472. http://www.jstor.org/pss/1830192

Golob, J.E., 1994. Does inflation uncertainty increase with inflation? Federal reserve Bank of Kansas City. Econ. Rev., 79: 27-27. http://www.kc.frb.org/publicat/econrev/pdf/3q94go lb.pdf

Holland, A.S., 1995. Inflation and uncertainty: Tests for temporal ordering. J. Money Credit Bank., 27: 827-837. http://www.jstor.org/pss/2077753

Johnson, D.R., 2002. The effect of inflation targeting on the behavior of expected inflation: Evidence from an 11 country panel. J. Monetary Econ., 49: 1521-1538. DOI: 10.1016/S0304-3932(02)00181-2

Nas, T.F. and M.J. Perry, 2000. Inflation, inflation uncertainty, and monetary policy in Turkey: 19601998. Contemp. Econ. Policy, 18: 170-180. DOI: 10.1111/j.1465-7287.2000.tb00015

Nelson, D.B., 1991. Conditional heteroskedasticity in asset returns: A new approach. Econometrica, 59: 347-370. http://www.jstor.org/pss/2938260

Neyapti, B., 2000. Inflation and Inflation Uncertainty in Turkey: Evidence from the Past Two Decades. Bilkent University, Ankara, Turkey, pp: 1-7. http://www.bilkent.edu.tr/ neyapti/shortstudies/01 2000.pdf

Okun, A.M., 1971. The mirage of steady inflation. Brook. Papers Econ. Activ., 2: 485-498. http://www.jstor.org/stable/2534234

Thornton, J., 2008. Inflation and inflation uncertainty in Argentina 1810-2005. Econ. Lett., 98: 247-252. DOI: 10.1016/j.econlet.2007.04.034 